\title{
What puts heart failure patients at risk for poor medication adherence?
}

This article was published in the following Dove Press journal:

Patient Preference and Adherence

17 July 2014

Number of times this article has been viewed

\author{
George J Knafl' \\ Barbara Riegel ${ }^{2,3}$ \\ 'School of Nursing, University \\ of North Carolina at Chapel Hill, \\ Chapel Hill, NC, USA; ${ }^{2}$ School \\ of Nursing, University of Pennsylvania, \\ Philadelphia, PA, USA; ${ }^{3}$ Leonard Davis \\ Institute, University of Pennsylvania, \\ Philadelphia, PA, USA
}

Background: Medication nonadherence is a major cause of hospitalization in patients with heart failure (HF), which contributes enormously to health care costs. We previously found, using the World Health Organization adherence dimensions, that condition and patient level factors predicted nonadherence in HF. In this study, we assessed a wider variety of condition and patient factors and interactions to improve our ability to identify those at risk for hospitalization.

Materials and methods: Medication adherence was measured electronically over the course of 6 months, using the Medication Event Monitoring System (MEMS). A total of $242 \mathrm{HF}$ patients completed the study, and usable MEMS data were available for 218 (90.1\%). Participants were primarily white (68.3\%), male (64.2\%), and retired (44.5\%). Education ranged from 8-29 years (mean, 14.0 years; standard deviation, 2.9 years). Ages ranged from 30-89 years (mean, 62.8 years; standard deviation, 11.6 years). Analyses used adaptive methods based on heuristic searches controlled by cross-validation scores. First, individual patient adherence patterns over time were used to categorize patients in poor versus better adherence types. Then, risk factors for poor adherence were identified. Finally, an effective model for predicting poor adherence was identified based on identified risk factors and possible pairwise interactions between them.

Results: A total of 63 (28.9\%) patients had poor adherence. Three interaction risk factors for poor adherence were identified: a higher number of comorbid conditions with a higher total number of daily medicines, older age with poorer global sleep quality, and fewer months since diagnosis of HF with poorer global sleep quality. Patients had between zero and three risk factors. The odds for poor adherence increased by 2.6 times with a unit increase in the number of risk factors (odds ratio, 2.62; 95\% confidence interval, 1.78-3.86; $P<0.001$ ).

Conclusion: Newly diagnosed, older HF patients with comorbid conditions, polypharmacy, and poor sleep are at risk for poor medication adherence. Interventions addressing these specific barriers are needed.

Keywords: heart failure, medication adherence, multiple chronic conditions, risk factors, self-care, sleep quality

\section{Introduction}

Heart failure (HF) affects more than five million adults (12\% of older adults) in the United States. ${ }^{1}$ For patients, the symptoms of fatigue, shortness of breath, depression, poor memory, and impaired sleep make HF burdensome. ${ }^{2}$ Symptoms drive hospitalization: one in four HF patients is readmitted to a hospital within 30 days of hospital discharge, and almost half are readmitted within 6 months. ${ }^{3}$ These hospitalizations are the primary contributor to the staggering medical cost of HF: $\$ 30.7$ billion annually. ${ }^{4}$ This cost is projected to increase more than twofold by 2030, making HF the most expensive condition billed to Medicare. ${ }^{5}$

A variety of reasons for HF hospitalization have been described, but as noted by Desai and Stevenson ${ }^{6}$ a robust and actionable model of risk factors for hospitalization is needed. In a prior study, we developed an effective model of risk factors for
Correspondence: Barbara Riegel School of Nursing, University of Pennsylvania, 418 Curie Boulevard, Philadelphia, PA 19104-4217, USA

$\mathrm{Tel}+\mathrm{I} 2158989927$

Fax +I 2402827707

Email briegel@nursing.upenn.edu 
hospitalization and demonstrated that medication nonadherence was the best predictor of hospitalization in a sample of HF patients, after considering numerous demographic, support, clinical, symptom, cognitive, and self-care factors. ${ }^{7}$ This result is not surprising, in that most authors have found medication nonadherence rates between $40 \%$ and $60 \%$ in patients with HF. ${ }^{8}$ At this point, the urgent need is to identify modifiable factors associated with medication nonadherence.

In the prior study, we used recently developed adaptive modeling methods to analyze objectively measured medication adherence as collected prospectively, using the Medication Event Monitoring System (MEMS ${ }^{\circledR}$; AARDEX Group Ltd, Sion, Switzerland), which records the date and time of each opening of the MEMS device, and presumably the taking of a dose of the associated medication. We identified individual patient medication adherence patterns over time and clustered these patterns into adherence types. ${ }^{7}$ These adherence types were used to identify the two categories of poor versus (vs) better adherence, an approach that is distinctly more sensitive than categorizations of adherence based on percentage prescribed doses taken (eg, $<80 \%$ vs $\geq 80 \%$ ). This nuanced approach contributed significantly to the predictive capability of the model for hospitalization, which had excellent discrimination characteristics. ${ }^{7}$ In this article, we build on previously identified individual patient adherence patterns and types and describe risk factors for poor adherence.

This is a second article exploring predictors of medication adherence in HF patients. In the first article, we used the World Health Organization ${ }^{9}$ dimensions of adherence (socioeconomic, condition, therapy, patient, and health care system) to focus our analyses. ${ }^{10}$ These dimensions reflect the types of variables found to predict treatment adherence in various populations. ${ }^{11,12}$ In our first study of HF patients, we determined that patient and condition characteristics contributed most to a steep decline in medication adherence. Patients with lapses in attention (odds ratio [OR], 2.65; $P=0.023$ ), excessive daytime sleepiness (OR, $2.51 ; P=0.037)$, and two or more medication dosing intervals per day (OR, 2.59; $P=0.016$ ) were more likely to have a steep decline in adherence over time than to have persistent adherence. ${ }^{10}$ However, as only a select group of possible predictors was tested in that study and no interactions were explored, in this current study, we build on our earlier work by assessing a wider variety of available conditions and patient-level risk factors for poor adherence. The purpose of this work is to identify risk factors associated with medication adherence problems in HF patients, with the ultimate goal of identifying and implementing interventions that address important barriers to adherence, and so reduce the chance of hospitalization. This purpose will be addressed in three steps: identify individual risk factors for poor adherence, identify a multiple risk factors model for poor adherence, and identify a multiple risk factors and interactions model for poor adherence.

\section{Materials and methods}

This was a secondary analysis of adherence data from a prospective cohort study of a consecutive sample of 280 adults with a confirmed diagnosis of HF enrolled from three outpatient sites in the northeastern United States; 242 (86.4\%) of these patients completed the 6-month study. ${ }^{13}$ Institutional review board approval was obtained at the University of Pennsylvania, the participating sites where we enrolled participants, and the University of North Carolina at Chapel Hill, and all participants gave informed consent. The primary objective of the parent study was to clarify the extent to which excessive daytime sleepiness influences HF self-care and clinical outcomes and the mechanism of the effect. Study methods have been described previously. ${ }^{13}$ Participants were preferentially sampled for variability in daytime sleepiness and cognition. Patients with severe depression, dementia (Telephone Interview for Cognitive Status [TICS] scores $\leq 24^{14}$ ), renal failure requiring dialysis, terminal illness, or history of serious drug or alcohol abuse within the past year were excluded. Because the parent study focused on sleepiness, patients with night-shift responsibilities were excluded. Study participants were followed-up for 6 months, with home visits at baseline, 3, and 6 months, where data were collected by research assistants. A list of all medications taken, including over-the-counter and as-needed medications, was made on the basis of visual assessment by the research assistant during the home visit. As almost half of all HF patients are readmitted to a hospital within 6 months, a 6-month interval was deemed adequate for follow-up. ${ }^{3,6,15}$ Nurses abstracted clinical information, including comorbid conditions, from medical records. All data were collected between 2007 and 2009.

\section{Measures}

Medication adherence was assessed using MEMS, a valid method of measuring medication-taking behavior. ${ }^{16,17}$ Methods used to collect these MEMS data have been described in detail elsewhere, ${ }^{10}$ but MEMS data were collected for a single selected medication scheduled to be taken one to three times daily. Our preference was that the MEMS be used with a medication taken in multiple daily doses, but sometimes negotiation was necessary when the medication to be used in the device was chosen. Only one medication was monitored, a practice 
that has been shown to be adequate because a single drug can be used to illustrate medication-taking patterns. ${ }^{18,19}$ Most patients $(56.7 \%)$ put their beta-blocker in the device, but $15.2 \%$ put an angiotensin-converting-enzyme inhibitor in it. Putting a diuretic in the device was strongly discouraged, and only seven patients $(3.2 \%)$ put their diuretic in the MEMS. MEMS data were downloaded for each patient at 3 and 6 months and were cleaned based on patient diaries, with clarification provided by telephone as needed. Specifically, patients were asked to note in their research diary whether something unusual happened that gave misleading data. An example would be that, after refilling a prescription, the device was opened an extra time that day to fill it with medicine. These types of incidents were captured in the diary and adjusted in the raw data. Participants were fully informed about the MEMS device, but telling patients that their medication dosing will be monitored is not sufficient to change behavior significantly. ${ }^{20}$

The World Health Organization ${ }^{9}$ dimensions of adherence (socioeconomic, condition, therapy, patient, and health care system) were used to focus the choice of additional indicators of the most promising dimensions and patient-related and condition-related factors. Patient-related variables were grouped into the categories of demographic (Table 1) and social support (Table 2). Condition-related factors were classified as clinical (Table 3), self-care (Table 4), symptom (Table 5), and cognition
(Table 6) variables. Only baseline values for these variables were used in analyses. A variety of standard scales were considered; these scales and their psychometric properties are summarized in Table 7 . Cognition was measured by a battery of neuropsychological tests, including the Digit Symbol Substitution Test, the Letter Number Sequencing subtest, the Probed Memory Recall Task, and the Trail Making Test: A and B. ${ }^{21}$ The non-scale-based variables of Tables 1-6 are self-explanatory.

Some variables were derived from investigator-generated lists such as the Compensatory Activities Score. Participants were presented with a list of behaviors used by patients (eg, lists) and support persons (eg, reminders) to compensate for memory problems. The number endorsed was used to compute the Compensatory Activities Score. Fatigue was measured as the sum of two items from the Kansas City Cardiomyopathy Questionnaire. ${ }^{22}$ These items ask how many times fatigue has limited the ability to do activities and how bothersome fatigue has been. Each item is scored 1 to 7 . Fatigue scores ranging from 2 to 14 were reversed so that higher scores indicate more fatigue. The alpha coefficient of the fatigue measure was 0.90 .

\section{Data analysis}

In our prior study using adaptive methods ${ }^{23}$ to model the effect of medication adherence on hospitalization for the

Table I Summary statistics for available demographic variables

\begin{tabular}{|c|c|c|}
\hline Variable and observed range & n (\%)* & Mean (SD; n)* \\
\hline \multicolumn{3}{|l|}{ Employment status } \\
\hline Retired & $97(44.5)$ & \\
\hline Unemployed or disabled & $62(28.4)$ & \\
\hline Employed (full or part time) & $59(27.1)$ & \\
\hline \multicolumn{3}{|l|}{ Sex } \\
\hline Male & $140(64.2)$ & \\
\hline Female & $78(35.8)$ & \\
\hline \multicolumn{3}{|l|}{ Income } \\
\hline Do not have enough & $35(16.1)$ & \\
\hline Have enough or more & $183(83.9)$ & \\
\hline \multicolumn{3}{|l|}{ Insurance } \\
\hline Government or none & $122(56.0)$ & \\
\hline Commercial or health maintenance organization & $96(44.0)$ & \\
\hline \multicolumn{3}{|l|}{ Race } \\
\hline Nonwhite & $69(31.7)$ & \\
\hline White & $149(68.3)$ & \\
\hline \multicolumn{3}{|l|}{ Age } \\
\hline $30-89$ & & $62.8(11.6 ; 218)$ \\
\hline \multicolumn{3}{|l|}{ ANART score } \\
\hline $0-49$ & & $31.0(11.2 ; 218)$ \\
\hline \multicolumn{3}{|l|}{ Years of education } \\
\hline $8-29$ & & $14.0(2.9 ; 218)$ \\
\hline
\end{tabular}

Note: *Out of 218 patients with some Medication Event Monitoring System data.

Abbreviations: SD, standard deviation; ANART, American National Adult Reading Test. 
Table 2 Summary statistics for available social support variables

\begin{tabular}{ll}
\hline Variable and observed range & Mean (SD; $\mathbf{n})^{*}$ \\
\hline Living alone & $48(22.0)$ \\
Yes & $170(78.0)$ \\
No & $88(40.4)$ \\
Marital status & $130(59.6)$ \\
$\quad$ Single, divorced, separated, or widowed & $75(34.4)$ \\
$\quad$ Married or partnered & $143(65.6)$ \\
Quality of support & \\
$\quad$ Satisfactory to good & \\
$\quad$ Very good & \\
MSPSS score & \\
I4-84 &
\end{tabular}

Note: *Out of 218 patients with Medication Event Monitoring System data.

Abbreviations: SD, standard deviation; MSPSS, Multidimensional Scale of Perceived Social Support.

same adherence data, we identified seven adherence types. ${ }^{7}$ First, individual adherence patterns were generated for each patient, consisting of possibly nonlinear mean adherence and adherence variability curves over time. These adherence patterns were adjusted for prescribed medication rates so that the ideal adherence pattern had mean adherence 1 at each time, with no variability. Then, these patterns were clustered into seven adherence types consisting of patients with similar

Table 3 Summary statistics for available clinical variables

\begin{tabular}{|c|c|c|}
\hline Variable and observed range & n (\%)* & Mean (SD; $\mathbf{n}) *$ \\
\hline \multicolumn{3}{|l|}{ Exercise } \\
\hline None & $36(16.5)$ & \\
\hline Some & $182(83.5)$ & \\
\hline \multicolumn{3}{|l|}{ Body mass index, $\mathrm{kg} / \mathrm{m}^{2}$} \\
\hline $15-67$ & & $30.8(7.9 ; 218)$ \\
\hline \multicolumn{3}{|l|}{ Blood urea nitrogen } \\
\hline $6-97$ & & $24.8(|3.8 ; 2| 6)$ \\
\hline \multicolumn{3}{|l|}{ Charlson total } \\
\hline $1-11$ & & $2.7(1.8 ; 218)$ \\
\hline \multicolumn{3}{|l|}{ Comorbidities } \\
\hline $0-9$ & & $3.0(2.1 ; 218)$ \\
\hline \multicolumn{3}{|l|}{ Creatinine } \\
\hline $0.5-3.4$ & & $1.3(0.5 ; 215)$ \\
\hline \multicolumn{3}{|l|}{ Diastolic blood pressure } \\
\hline $45-103$ & & $68.9(110.8 ; 216)$ \\
\hline \multicolumn{3}{|l|}{ Ejection fraction } \\
\hline $5-80$ & & $35.8(17.4 ; 217)$ \\
\hline \multicolumn{3}{|l|}{ Hemoglobin } \\
\hline $8.1-18.4$ & & I3.I (I.8; 209) \\
\hline \multicolumn{3}{|l|}{ Months since heart failure diagnosis } \\
\hline $0-508$ & & $76.2(75.5 ; 203)$ \\
\hline \multicolumn{3}{|l|}{ Pulse } \\
\hline $42-100$ & & $69.8(11.5 ; 218)$ \\
\hline \multicolumn{3}{|l|}{ Serum sodium } \\
\hline$|3|-\mid 46$ & & $139.1(2.9 ; 213)$ \\
\hline \multicolumn{3}{|l|}{ Systolic blood pressure } \\
\hline $80-176$ & & $116.0(17.5 ; 217)$ \\
\hline
\end{tabular}

Note: *Out of 218 patients with some Medication Event Monitoring System data. Abbreviation: SD, standard deviation. adherence patterns. The best combination of these seven adherence types for predicting hospitalization was the dichotomous adherence type of poor adherence (ie, with very low adherence some time during study participation) versus better adherence (ie, primarily moderate or better levels of adherence throughout study participation). This dichotomous poor adherence type is modeled in reported analyses.

In this study, adaptive methods ${ }^{23}$ were used to identify risk factors, individually and in combination, for poor adherence, as previously identified from MEMS adherence data. ${ }^{7}$ Adaptive methods have been used previously for modeling adherence for HIV-positive patients, ${ }^{24,25}$ hypertensive patients, ${ }^{26}$ and HF patients. ${ }^{7}$ These methods use k-fold likelihood cross-validation (LCV) scores for model selection. The data are randomly partitioned into $\mathrm{k}$ distinct subsets, called folds. Likelihoods are computed for each fold, using parameter estimates for the data in the other folds. These deleted fold likelihoods are then combined into a LCV score, with larger scores indicating better models for the data. LCV scores provide for an objective evaluation of models, independent of the size of estimated parameter values (such as ORs for logistic regression models) and of $P$-values. Reported analyses used 10-fold LCV scores computed from likelihoods for logistic regression models.

The model with the largest LCV score is not always the best choice. A less-complex model may be preferable if the reduction in the LCV score is insubstantial (nonsignificant or indistinct). LCV ratio tests, analogous to likelihood ratio tests, can be used to make such assessments. Although these are $\chi^{2}$-based tests, they are expressed in terms of a cutoff for a substantial (significant or distinct) percentage decrease in the LCV score. A model generating a percentage decrease in the LCV score greater than this cutoff is substantially improved on by the model with the larger LCV score. 
Table 4 Summary statistics for available self-care variables

\begin{tabular}{|c|c|c|}
\hline Variable and observed range & $\mathbf{n}(\%) *$ & Mean (SD; $\mathbf{n}) *$ \\
\hline \multicolumn{3}{|c|}{ Prescribed rate for medication controlled by MEMS } \\
\hline $2-3$ & $133(6 \mid .0)$ & \\
\hline I & $85(39.0)$ & \\
\hline \multicolumn{3}{|l|}{ DHFKS score } \\
\hline $7-15$ & & $11.7(1.6 ; 211)$ \\
\hline \multicolumn{3}{|l|}{ SCHFI self-care confidence } \\
\hline $42-100$ & & $75.7(14.4 ; 218)$ \\
\hline \multicolumn{3}{|l|}{ SCHFI self-care maintenance } \\
\hline $32-92$ & & $66.8(11.6 ; 215)$ \\
\hline \multicolumn{3}{|l|}{ SCHFI self-care management } \\
\hline $29-100$ & & $66.1(18.6 ; 94)^{* *}$ \\
\hline \multicolumn{3}{|l|}{ Total medications } \\
\hline $1-25$ & & $9.9(3.9 ; 218)$ \\
\hline
\end{tabular}

Notes: *Out of patients with available MEMS data; **patients with missing SCHFI self-care management values were those with no symptoms to manage.

Abbreviations: SD, standard deviation; MEMS, Medication Event Monitoring System; DHFKS, Dutch Heart Failure Knowledge Score; SCHFI, Self-Care of Heart Failure Index.

In contrast, a model generating a percentage decrease in the LCV score less than or equal to the cutoff is a competitive alternative to the model with the larger LCV score. If the model with the lower score is also less complex, then it is a parsimonious, competitive alternative and, thus, preferable. For example, if the constant model for predicting adherence generates an insubstantial percentage decrease in the LCV score in comparison with the model based on a specific risk factor, then the constant model is preferable, and so the risk factor is not a substantive predictor of adherence. The cutoff changes with the sample size.

Patients with poor adherence were characterized by identifying risk factors for poor adherence from among the variables of Tables 1-6. Categorical variables were used as reported. For each continuous and ordinal variable, observed values were categorized into lower versus higher values, using each observed value as a cutoff. The cutoff with the best (largest) LCV score was used to determine the associated

Table 5 Summary statistics for available symptom variables

\begin{tabular}{|c|c|c|}
\hline Variable and observed range & n (\%)* & Mean (SD; n)* \\
\hline \multicolumn{3}{|l|}{ General health perception } \\
\hline Poor & $24(11.0)$ & \\
\hline Fair to excellent & $194(89.0)$ & \\
\hline \multicolumn{3}{|l|}{ Health compared with a year ago } \\
\hline Poor & $17(7.8)$ & \\
\hline Fair to excellent & $20 \mathrm{I}(92.2)$ & \\
\hline \multicolumn{3}{|c|}{ Trouble breathing or ankle swelling within past month } \\
\hline Yes & $94(43.1)$ & \\
\hline No & $124(56.9)$ & \\
\hline \multicolumn{3}{|l|}{ NYHA class } \\
\hline IV & $4 I(18.8)$ & \\
\hline I-III & I77 (8I.2) & \\
\hline \multicolumn{3}{|l|}{ Fatigue } \\
\hline $2-13$ & & $6.4(3.0 ; 218)$ \\
\hline \multicolumn{3}{|l|}{ SSS score } \\
\hline $1-6$ & & $2.2(1.2 ; 218)$ \\
\hline \multicolumn{3}{|l|}{ ESS score } \\
\hline $0-23$ & & $6.7(4.5 ; 218)$ \\
\hline \multicolumn{3}{|l|}{ PSQI global sleep score } \\
\hline $0-19$ & & $7.1(4.0 ; 218)$ \\
\hline \multicolumn{3}{|l|}{ PHQ total } \\
\hline $0-18$ & & $4.4(3.6 ; 218)$ \\
\hline
\end{tabular}

Note: *Out of 218 patients with some Medication Event Monitoring System data.

Abbreviations: SD, standard deviation; NYHA, New York Heart Association; SSS, Stanford Sleepiness Scale; ESS, Epworth Sleepiness Scale; PSQI, Pittsburgh Sleep Quality Index; PHQ, Patient Health Questionnaire. 
Table 6 Summary statistics for available cognition variables

\begin{tabular}{|c|c|}
\hline Variable and observed range & Mean $(S D ; n) *$ \\
\hline \multicolumn{2}{|l|}{ CAS } \\
\hline $0-23$ & $9.4(4.4 ; 218)$ \\
\hline \multicolumn{2}{|l|}{ DSST score } \\
\hline $11-96$ & $54.4(16.7 ; 217)$ \\
\hline \multicolumn{2}{|l|}{ LNS score } \\
\hline $1-20$ & $8.9(3.4 ; 214)$ \\
\hline \multicolumn{2}{|l|}{ PMR score } \\
\hline $0-4$ & $2.1(1.2 ; 217)$ \\
\hline \multicolumn{2}{|l|}{ PVT lapses } \\
\hline $0-79$ & $7.8(12.4 ; 2 \mid 4)$ \\
\hline \multicolumn{2}{|l|}{ TICS score } \\
\hline $26-40$ & $33.8(2.9 ; 218)$ \\
\hline \multicolumn{2}{|l|}{ TMTA score } \\
\hline $14-120$ & $41.5(17.3 ; 218)$ \\
\hline \multicolumn{2}{|l|}{ TMTB score } \\
\hline $8-300$ & $105.3(53.3 ; 2 \mid 7)$ \\
\hline \multicolumn{2}{|l|}{ Dimensions cognitively impaired } \\
\hline $0-5$ & $1.6(1.0 ; 218)$ \\
\hline
\end{tabular}

Note: *Out of 218 patients with some Medication Event Monitoring System data. Abbreviations: SD, standard deviation; CAS, Compensatory Activities Score; DSST, Digit Symbol Substitution Test; LNS, Letter Number Sequencing; PMR, Probed Memory Recall; PVT, Psychomotor Vigilance Task; TICS, Telephone Interview for Cognitive Status;TMTA, Trail Making Test:A;TMTB, Trail Making Test: B.

potential risk factor. The risk factor category corresponded to the range of values generating an OR greater than 1 for poor adherence. When a predictor had missing values, those observations were conservatively assigned to the non-risk factor category. In this way, all patients having an identified risk factor had non-missing values for the associated predictor. Cutoffs with less than $10 \%$ of the observations in either the lower or higher categories were excluded to avoid sparse cases.

Categorizing continuous/ordinal variables into dichotomous risk factors has the advantage of allowing for missing values without loss of data and of having a practical clinical interpretation. However, the disadvantage is possible loss of information. Whether substantial information has been lost or not can be assessed by comparing LCV scores for a dichotomous risk factor model with the model based on the associated continuous/ordinal variable. This is only possible if that variable has no missing values, as LCV scores are only comparable when based on the same set of data.

Bivariate models were generated for all potential risk factors. Then a multiple risk factors model was generated, using the adaptive modeling process of Knafl et $\mathrm{al}^{23}$ considering only the risk factors with significant $(P<0.05)$ bivariate effects. This adaptive modeling process has been described elsewhere. ${ }^{7,26}$ In this case, the process first adds risk factors systematically to the model and then contracts the expanded model to remove extraneous risk factors, if any, using a LCV ratio test to decide when to stop the contraction.

Next, an adaptive model was generated with this same process, but considering the same set of risk factors as well as possible pairwise interactions between any two of them to obtain an assessment of the effect of interactions between risk factors. Pairwise interactions holding for less than $10 \%$ of the observations were excluded to avoid sparse cases. Finally, this latter model was used to compute a risk index for poor adherence for patients as the count of that model's risk factors and risk factor interactions.

\section{Results \\ Sample}

Usable MEMS data were available for 218 (90.1\%) of the 242 parent study subjects who completed that study. Summary statistics for the patients with usable MEMS data are presented in Tables 1-6 for available variables within the six categories described earlier. For example, patients were primarily white (68.3\%), male (64.2\%), and retired (44.5\%). Education ranged from 8-29 years, with a mean of 14.0 years (standard deviation, 2.9 years), whereas ages ranged from 30-89 years, with a mean of 62.8 years (standard deviation, 11.6 years). A total of 63 (28.9\%) of the patients with usable MEMS data had poor medication adherence.

\section{Risk factors for poor adherence}

Table 8 presents results for characterizing poor adherence, considering the variables of Tables $1-6$, one at a time. Individual risk factor analyses identified 12 significant $(P<0.05)$ individual risk factors for poor adherence, including one demographic, zero social support, three clinical, one selfcare, four symptom, and three cognition risk factors. The cutoff for a substantial percentage decrease in LCV scores for these analyses is $0.88 \%$. The percentage decrease for the constant model exceeds this cutoff for only two (16.7\%) of the twelve variables (LCV scores not reported), indicating that $\mathrm{LCV}$ ratio tests are more conservative than tests for zero coefficients, and thus are similar in effect to multiple comparisons procedures.

There are five continuous/ordinal variables with no missing values generating individual risk factors in Table 8 . For two of these variables (number of comorbidities and TICS score), the LCV scores were better for the individual linear models, but with insubstantial percentage decreases for the associated individual risk factor model ( 0.55357 vs 0.55543 and 0.54778 vs 0.54826 , with percentage decreases of $0.33 \%$ and $0.09 \%$, respectively). For two other of these variables 
Table 7 Summary of each standard scale used

\begin{tabular}{|c|c|c|}
\hline Scale name & Description & Psychometric properties \\
\hline $\begin{array}{l}\text { American National Adult } \\
\text { Reading Test (ANART) })^{53,54}\end{array}$ & $\begin{array}{l}\text { Measure of premorbid, crystalized intellect. A list of } \\
50 \text { phonetically irregular words (eg, aisle) is read aloud. } \\
\text { The number of words pronounced correctly is used } \\
\text { as the score. }\end{array}$ & $\begin{array}{l}\text { Reliabilityby Cronbach's alpha was } 0.93 \text {. Validity was } \\
\text { demonstrated by comparing with the Wechsler Adult } \\
\text { Intelligence Scale-Revised (WAIS-R) vocabulary test; } \\
\text { coefficient was } 0.75 \text {. }\end{array}$ \\
\hline $\begin{array}{l}\text { Multidimensional Scale of } \\
\text { Perceived Social Support } \\
\text { (MSPSS) })^{55,56}\end{array}$ & $\begin{array}{l}\text { A I2-item measure assessing social support from } \\
\text { family, friends, and a significant other. Responses range } \\
\text { from I (very strongly disagree) to } 7 \text { (very strongly } \\
\text { agree), with higher scores indicating more perceived } \\
\text { support. }\end{array}$ & $\begin{array}{l}\text { Reliability coefficients range from } 0.85-0.91 \text {. Factorial } \\
\text { validity has been confirmed repeatedly. }\end{array}$ \\
\hline Charlson Comorbidity Index ${ }^{57}$ & $\begin{array}{l}\text { Seventeen broad categories of conditions scored } \\
\text { with I-6 points. Scores range from 0-34 and can be } \\
\text { classified as low, moderate, and high comorbidity. }\end{array}$ & $\begin{array}{l}\text { Established validity for predicting mortality, } \\
\text { complications, health care resource use, length of } \\
\text { hospital stay, discharge disposition, and cost. }\end{array}$ \\
\hline $\begin{array}{l}\text { Dutch Heart Failure } \\
\text { Knowledge Score }{ }^{58}\end{array}$ & $\begin{array}{l}\text { Fifteen items measuring general knowledge of HF } \\
\text { and knowledge of HF treatments, HF symptoms, and } \\
\text { symptom recognition. }\end{array}$ & $\begin{array}{l}\text { Items based on established patient education } \\
\text { guidelines of the Netherlands Heart Foundation, } \\
\text { which mirror those of the American Heart } \\
\text { Association. }\end{array}$ \\
\hline $\begin{array}{l}\text { Self-Care of Heart Failure } \\
\text { Index (SCHFI V6.2) }\end{array}$ & $\begin{array}{l}\text { Twenty-two items, measured using a four-point self- } \\
\text { report response format, which form three scales: self- } \\
\text { care maintenance, management, and confidence. }\end{array}$ & $\begin{array}{l}\text { Internal consistency tested by factor score } \\
\text { determinacy, coefficients all }>0.70 \text {. Moderate to high } \\
\text { correlations over time in test-retest reliability testing. } \\
\text { Construct validity has been demonstrated. The SCHFI } \\
\text { is sensitive to subtle behavioral changes in a variety of } \\
\text { HF samples. }\end{array}$ \\
\hline $\begin{array}{l}\text { Epworth Sleepiness Scale } \\
(\text { ESS })^{60}\end{array}$ & $\begin{array}{l}\text { A measure of global or typical sleepiness. Respondents } \\
\text { rate the likelihood of falling asleep in eight soporific } \\
\text { situations using a four-point Likert scale ranging from } \\
\text { never dozing }(0) \text { to high chance of dozing (3). }\end{array}$ & $\begin{array}{l}\text { Test-retest reliability ( } r=0.82) \text { and internal } \\
\text { consistency }(\alpha=0.88) \text { have been established. Single } \\
\text { factor structure. ESS correlates significantly with the } \\
\text { frequency of apneas and has a sensitivity of } 93.5 \% \text { and } \\
\text { a specificity of } 100 \% \text { for distinguishing pathological } \\
\text { from normal sleepiness. }\end{array}$ \\
\hline Stanford Sleepiness Scale ${ }^{61}$ & $\begin{array}{l}\text { The Stanford Sleepiness Scale provides a rating of } \\
\text { sleepiness at a particular moment in time. Current } \\
\text { degree of sleepiness is rated I (vital, alert, or wide- } \\
\text { awake) to } 7 \text { (feeling that sleep onset is soon). }\end{array}$ & $\begin{array}{l}\text { Sensitive to both sleep deprivation and time of } \\
\text { day. Reliability tested as the correlation between } \\
\text { alternative forms was adequate }(0.88) \text {. }\end{array}$ \\
\hline $\begin{array}{l}\text { Patient Health Questionnaire } \\
(\mathrm{PHQ}-9)^{27}\end{array}$ & $\begin{array}{l}\text { The PHQ- } 9 \text { is a measure of depression. Scores of } 5 \text {, } \\
10,15 \text {, and } 20 \text { represent mild, moderate, moderately } \\
\text { severe, and severe depression, respectively. }\end{array}$ & $\begin{array}{l}\text { Reliable and valid in numerous populations including } \\
\text { HF. }\end{array}$ \\
\hline $\begin{array}{l}\text { Pittsburgh Sleep Quality Index } \\
\text { (PSQI) }\end{array}$ & $\begin{array}{l}\text { A self-report measure of the perception of habitual } \\
\text { sleep quality measuring seven domains for the prior } \\
\text { month: I) sleep quality; } 2 \text { ) latency; } 3 \text { ) duration; } \\
4 \text { ) habitual sleep efficiency; } 5 \text { ) use of sleep medications; } \\
\text { 6) disturbance; and } 7 \text { ) daytime dysfunction. A global } \\
\text { score (0-2I points) is obtained by summing scale } \\
\text { domain scores. Higher scores indicate poorer global } \\
\text { sleep quality. }\end{array}$ & $\begin{array}{l}\text { Internal consistency reliability is in the range of } \\
0.77-0.83 \text {. In test-retest reliability testing, scores } \\
\text { were not significantly different. PSQI scores have been } \\
\text { validated by comparison with polysomnography and } \\
\text { shown to discriminate among known groups. }\end{array}$ \\
\hline $\begin{array}{l}\text { Psychomotor Vigilance Test } \\
(\text { PVT })^{63}\end{array}$ & $\begin{array}{l}\text { Measure of simple attention. Subjects press a button } \\
\text { in response to a series of red digits " } 000 \text { " in an } \\
\text { automated light-emitting diode counter window of a } \\
\text { small, portable device. Signals are presented at random } \\
\text { intervals over a 10-minute period. Metrics involving } \\
\text { response speed and lapses are the best primary } \\
\text { outcomes for the 10-min PVT. }\end{array}$ & Highly sensitive measure of sleep deprivation. \\
\hline
\end{tabular}

Abbreviation: HF, heart failure.

(age and total medications), the LCV scores were worse for the individual linear models, but with insubstantial percentage decreases compared with the associated individual risk factor model ( 0.54820 vs 0.55160 and 0.54622 vs 0.54894 , with percentage decreases $0.62 \%$ and $0.50 \%$, respectively). For the fifth variable (Patient Health Questionnaire ${ }^{27}$ total score), the LCV score was worse for the individual linear model and with a substantial percentage decrease compared 
with the associated individual risk factor model $(0.54308$ vs 0.54857 , with percentage decrease $1.00 \%$ ). These results indicate that, in this case, consideration of dichotomous risk factors does not result in loss of predictive capability over associated linear models. Further, sometimes dichotomous factors even provide distinct improvements in predictive capability.

The adaptive multiple risk factors model, generated considering the twelve significant risk factors of Table 8 , had three risk factors: higher Trail Making Test: B, a measure of complex attention $(P=0.002 ; \mathrm{OR}, 3.36$; $95 \%$ confidence interval $[\mathrm{CI}], 1.56-7.25)$; higher number of comorbid conditions ( $P=0.025$; OR, 2.04; 95\% CI, 1.09-7.25); and lower HF duration $(P=0.007$; OR, 2.61; 95\% CI, 1.30-5.22). The LCV score was 0.56824 . In contrast, the best individual risk factor model based on a higher Trail Making Test: B score had an LCV score of 0.55545 , with a substantial percentage decrease of $2.25 \%$, indicating that the multiple risk factors model substantially improved on each of the individual risk factor models.

The adaptive modeling process is based on LCV scores, so individual risk factors with large ORs need not be included in the adaptively generated multiple risk factor model, unless those risk factors also generate large LCV scores. For example, the risk factor based on a larger Pittsburgh Sleep Quality Index global sleep score generated the largest OR of 4.78 in Table 8 . However, it had the fourth largest LCV score among individual risk factors (scores not reported in Table 8) and was not included in the adaptively generated multiple risk model. In contrast, the risk factor based on a larger Trail Making Test: B score had the second largest OR of 3.51 in Table 8. However, it also had the largest LCV score among individual risk factor models and was included in the adaptively generated multiple risk factor model.

The adaptive model also considering pairwise risk factor interactions is described in Table 9. This model included three risk factor interactions (and no noninteraction risk factors): a higher number of comorbid conditions with a higher total number of medications, older age with poorer global sleep quality, and fewer months since diagnosis of heart failure (ie, less experience with the illness) with poorer global sleep quality. The c-index (also called the c-statistic; the same as the area under the receiver-operating characteristics curve) was 0.72 , which is considered acceptable discrimination. ${ }^{28}$ The LCV score for this model was 0.57665 . The noninteraction multiple risk factors model generated a substantial percentage decrease in the LCV score of $1.46 \%$, indicating that consideration of interactions provided a substantial improvement over only using noninteraction risk factors for predicting poor adherence.

To assess the possibility of collinearity between these three interactions, we computed logistic regression models

Table 8 Significant individual risk factor models of poor versus better adherence

\begin{tabular}{|c|c|c|c|c|c|}
\hline Variable & Factor & n (\%)* & $P$-value & OR & $95 \% \mathrm{Cl}$ \\
\hline \multicolumn{6}{|l|}{ Demographics } \\
\hline Age, years & $\geq 61$ vs $<61$ & $132(60.6)$ & 0.018 & 2.17 & $1.15-4.12$ \\
\hline \multicolumn{6}{|l|}{ Social support } \\
\hline \multicolumn{6}{|l|}{-} \\
\hline \multicolumn{6}{|l|}{ Clinical } \\
\hline Comorbidities & $\geq 4$ vs $<4$ & $87(39.9)$ & 0.008 & 2.26 & $1.24-4.10$ \\
\hline Months since heart failure & $\leq 2 \mathrm{I}$ vs $>2 \mathrm{I}$ or missing & $50(22.9)$ & 0.008 & 2.43 & $|.26-4.7|$ \\
\hline Diastolic blood pressure & $\geq 82$ vs $<82$ or missing & $22(10.1)$ & 0.026 & 2.77 & $1.13-6.77$ \\
\hline \multicolumn{6}{|l|}{ Self-care } \\
\hline Total medications & $\geq 9$ vs $<9$ & $132(60.6)$ & 0.038 & 1.95 & $1.04-3.68$ \\
\hline \multicolumn{6}{|l|}{ Symptoms } \\
\hline General health perception & Poor vs fair to excellent & $24(I 1.0)$ & 0.019 & 2.80 & I.19-6.64 \\
\hline $\begin{array}{l}\text { Trouble breathing or ankle } \\
\text { swelling within past month }\end{array}$ & Yes vs no & $94(43.1)$ & 0.040 & 1.86 & $1.03-3.35$ \\
\hline PHQ total & $\geq 10$ vs $<10$ & $22(10.1)$ & 0.026 & 2.80 & $1.13-6.77$ \\
\hline PSQI global sleep score & $\geq 3$ vs $<3$ or missing & $195(89.4)$ & 0.039 & 4.78 & $1.09-21.0$ \\
\hline \multicolumn{6}{|l|}{ Cognition } \\
\hline DSST score & $\leq 42$ vs $>42$ or missing & $55(25.2)$ & 0.016 & 2.21 & $1.16-4.21$ \\
\hline TICS score & $\leq 30$ vs $>30$ & $36(16.5)$ & 0.027 & 2.30 & $1.10-4.80$ \\
\hline TMTB score & $\geq \mid 48$ vs $<148$ or missing & $36(16.5)$ & 0.001 & 3.51 & I.68-7.33 \\
\hline
\end{tabular}

Note: *Out of 218 patients with some Medication Event Monitoring System data.

Abbreviations: OR, odds ratio; Cl, confidence interval; PHQ, Patient Health Questionnaire; PSQI, Pittsburgh Sleep Quality Index; DSST, Digit Symbol Substitution Test; TICS, Telephone Interview for Cognitive Status; TMTB, Trail Making Test: B; vs, versus. 
Table 9 Multiple Risk Factor Interactions Model for poor versus better adherence

\begin{tabular}{|c|c|c|c|c|c|c|c|c|}
\hline \multirow[t]{2}{*}{ Description } & \multicolumn{2}{|c|}{ Interaction term I } & \multicolumn{2}{|c|}{ Interaction term 2} & \multirow{2}{*}{$\begin{array}{l}\text { At risk group, } \\
\text { n (\%)* }\end{array}$} & \multirow{2}{*}{$P$-value } & \multirow[t]{2}{*}{ OR } & \multirow{2}{*}{$95 \% \mathrm{Cl}$} \\
\hline & Variable & Risk factor & Variable & Risk factor & & & & \\
\hline $\begin{array}{l}\text { Higher number of comorbidities } \\
\text { with higher total medications }\end{array}$ & Comorbidities & $\geq 4$ vs $<4$ & Total medications & $\geq 9$ vs $<9$ & $67(30.7)$ & 0.2 & 2.89 & $1.18-7.06$ \\
\hline $\begin{array}{l}\text { Older age with poorer global } \\
\text { sleep quality }\end{array}$ & Age & $\geq 6 \mathrm{I}$ vs $<6 \mathrm{I}$ & $\begin{array}{l}\text { PSQI global } \\
\text { sleep score }\end{array}$ & $\begin{array}{l}\geq 3 \text { vs }<3 \\
\text { or missing }\end{array}$ & $117(53.7)$ & 0.004 & 3.20 & I.45-7.07 \\
\hline $\begin{array}{l}\text { Fewer months since diagnosis of } \\
\text { heart failure with poorer global }\end{array}$ & $\begin{array}{l}\text { Months since } \\
\text { heart failure }\end{array}$ & $\begin{array}{l}\leq 21 \text { vs }>21 \\
\text { or missing }\end{array}$ & $\begin{array}{l}\text { PSQI global } \\
\text { sleep score }\end{array}$ & $\begin{array}{l}\geq 3 \text { vs }<3 \\
\text { or missing }\end{array}$ & $44(20.2)$ & 0.006 & 2.82 & $1.35-5.85$ \\
\hline
\end{tabular}

sleep quality

Note: *Out of 218 patients with some Medication Event Monitoring System data.

Abbreviations: OR, odds ratio; $\mathrm{Cl}$, confidence interval; PSQI, Pittsburgh Sleep Quality Index; vs, versus.

predicting each of these three dichotomous interactions as a function of the other two. The largest Nagelkerke $R^{2}$ value for these models was $4.5 \%$, indicating that collinearity was not a problem for the risk factor interactions model.

Patients had zero to three of the three interaction risk factors, with 69 (31.7\%) patients having none of the interaction risk factors, 78 (35.8\%) patients having one, 63 (28.9\%) patients having two, and eight (3.7\%) patients having three factors. For patients with poor adherence, percentages increased from $10.1 \%$ to $26.9 \%, 47.6 \%$, and $62.5 \%$ of the $69,78,63$, and eight patients with zero to three interaction risk factors, respectively. The risk index model based on the number of risk factor interactions as the only predictor of poor adherence had an LCV score 0.57954 . The risk factor interaction model was a parsimonious, competitive alternative with an insubstantial percentage decrease in the LCV score of $0.50 \%$. The c-index for the risk index model was acceptable, at 0.71 , and the estimated OR for a unit increase in the risk index variable was $2.62(95 \% \mathrm{CI}, 1.78-3.86$; $P<0.001)$.

\section{Discussion}

In this study, we characterized poor medication adherence, as determined from our prior assessment of electronically monitored patient adherence. ${ }^{7}$ Our major finding was that three pairs of interaction risk factors successfully predicted having poor versus better medication adherence levels: a higher number of comorbid conditions with a higher total number of medications, older age with poorer global sleep quality, and fewer months since diagnosis of heart failure with poorer global sleep quality. The addition of even one interaction risk factor increased the odds of poor adherence by about 2.6 times. Some of these risk factors are modifiable and provide direction for intervention.

These results differ in important ways from our prior analysis of predictors of MEMS-based adherence data. ${ }^{10}$
First, in that analysis, using growth mixture modeling, we identified two distinct patterns, and $22 \%$ of HF patients were in the "steep decline" or poorest medication-adherence group. In the current analysis, when the seven distinct types, accounting for both means adherence and adherence variability over time, as identified earlier, ${ }^{7}$ were collapsed into two types, $28.9 \%$ were in the poor medication adherence type. Second, having focused the analysis of contributors to a steep decline in adherence on a select group of variables suggested by the World Health Organization model, we identified only three contributors: lapses in attention, excessive daytime sleepiness, and two or more medication doses per day. Moreover, interactions were not considered. In this analysis, we tested more potential contributors in the promising dimensions of patient- and condition-related factors and assessed potential interactions. This approach revealed three specific pairs of interacting risk factors likely to increase the odds of medication nonadherence. Interestingly, the number of daily medication doses for the drug used in the MEMS device did not predict adherence, although this factor has been found repeatedly in other studies..$^{29,30}$ Perhaps this was a result of considering adherence variability along with mean adherence, rather than just mean adherence, in forming adherence types.

We found that a higher number of comorbid conditions plus more medications taken daily or polypharmacy, conventionally defined as the chronic use of five or more medications,${ }^{31}$ predicted poor medication adherence. These results are consistent with those of others who have found that more comorbid conditions and more pills taken each day predicted poor medication adherence. ${ }^{32} \mathrm{We}$ found previously that HF patients with multiple comorbid conditions find that differentiating the symptoms of multiple conditions is one of the most challenging self-care skills. ${ }^{33}$ Having multiple conditions also decreases self-efficacy or confidence in one's ability to perform specific self-care tasks such as medication 
taking. ${ }^{34}$ When intervention studies were examined in a systematic review, medication adherence increased most consistently with behavioral interventions that reduced medication dosing demands, ${ }^{35}$ illustrating that polypharmacy adds a level of complexity to life with multiple chronic conditions that predisposes patients to poor medication adherence. In fact, the essence of medication reconciliation, a popular approach for patients with multiple chronic conditions, involves analyzing and resolving medication discrepancies and typically decreases the number of pills taken daily. ${ }^{36}$

Another pair of risk factors for medication nonadherence was the interaction of older age and poorer sleep quality. We are not the first investigators to identify older age as a factor in nonadherence. ${ }^{5,15,37}$ Poor sleep quality is also known to impair the ability to pay attention and make good decisions. ${ }^{38,39}$ However, the interaction of older age and poor sleep quality may be best explained by the compelling mechanistic explanation described by Neupert et $\mathrm{al}^{37}$ who examined how daily fluctuations in cognition and busyness are related to daily fluctuations in forgetting to take medications and whether these within-person relationships differed for younger and older adults. On days when the older adults in their study were relatively less busy, they were at lower risk for forgetting to take their medicines, but only if they were also performing well on the everyday cognition assessments. This observation is consistent with our findings that poor sleep quality contributes to forgetting to take medications..$^{10,13}$ Together these results reinforce the salience of daily routines and lifestyle factors such as sleep routines, as they influence memory in older adults.

Finally, patients with a shorter duration of HF or less experience with the diagnosis and poor sleep quality were at higher risk for nonadherence. Others have demonstrated previously that patients who are newly diagnosed with HF struggle with self-care. ${ }^{40,41}$ Dickson et al described a typology in which novices lacked experience and skill in caring for their HF diagnosis. ${ }^{42}$ Knowing that attention and decisionmaking are impaired by poor sleep and that better decisions are made by people with illness experience, the interaction between shorter duration of HF and poor sleep quality in predicting nonadherence is not surprising.

Together, these results suggest that older age, multiple comorbid conditions, polypharmacy, lack of experience, and poor sleep quality put HF patients at risk for poor medication adherence. Fortunately, interventions addressing some of these predictors are available. Systematic evaluation and modification of the medication regimen (including over-thecounter medicines) in all HF patients could address many of the problems caused by polypharmacy. Multidrug combinations or "polypills" have been advocated as a solution to drug-drug interactions and poor treatment adherence. ${ }^{43} \mathrm{Lack}$ of experience is best addressed with education and support. We found previously that about 2 months after being diagnosed with HF, patients improve in their abilities to adhere to the treatment program, detect symptoms, and make good decisions about those symptoms. ${ }^{41}$ Steering newly diagnosed patients toward a sustainable routine during that 2-month period may decrease problems with medication adherence.

Surprisingly, interventions for poor sleep quality are the most challenging. For people with sleep apnea, continuous positive airway pressure is effective, but adherence to treatment is problematic. ${ }^{44}$ For people with insomnia, the most common treatments used are over-the-counter antihistamines, alcohol, and prescription medications such as benzodiazepine receptor agonists. ${ }^{45}$ These prescription hypnotics have been shown to have good short-term efficacy ${ }^{46}$ and good durability over time frames of up to 12 months, ${ }^{47,48}$ but clinical outcomes do not persist after treatment discontinuation, and issues such as rebound insomnia, dependence, abuse potential and respiratory depression ${ }^{49,50}$ make providers and patients hesitant to use them. Cognitive behavioral therapy for insomnia is effective, ${ }^{51}$ but it is initially time-intensive and costly, and not all patients are willing or able to engage in this form of psychotherapy. Research identifying other treatment options for the general population with poor sleep quality may have an added benefit of improving medication adherence.

Limitations of this study include possible selection bias, as the data were taken from a prospective cohort study in which patients were selected for variability in daytime sleepiness and cognitive function. In addition, as a group, these patients were younger and better educated than some community samples of HF patients. Future research is needed to test these results in more general populations. Because the analyses were exploratory, further research is needed to confirm these results. Further research is needed to investigate longitudinally both the effects of prior risk factors on adherence and of that adherence on subsequent risk factors. Adherence was measured with MEMS for a single HF medication. There is no guarantee that a dose of the medication was taken every time the MEMS device was opened. Moreover, adherence for medications not controlled by the MEMS has not been accounted for. These limitations are offset by several strengths. The statistical approach took into account patterns over time for both mean adherence and adherence variability, allowing a more nuanced understanding of medication adherence than prior studies. Other 
strengths include the prospective design and the objective measurement of medication adherence.

In conclusion, medication adherence is a continuing problem for which solutions are urgently needed. In this study, we identified three pairs of variables associated with nonadherence. Together, these three pairs suggest that clinicians caring for HF patients who are of older age, those with multiple comorbid conditions and taking numerous medications, and those who are newly diagnosed should anticipate problems with medication adherence and discuss ways to assist patients to avoid adherence problems. Asking patients about their sleep quality should be a routine element of all clinical encounters. ${ }^{52}$ Future research is needed to identify interventions that adequately address these predictors of nonadherence.

\section{Acknowledgments}

The authors gratefully acknowledge Megan Patey, RN, BSN, for her assistance with preparation of the data for analysis and Dr Harleah Buck for her insightful review of a prior draft of this article. This work was funded in part by a grant from the National Heart, Lung and Blood Institute (R01 HL084394-01A1) and by the Philadelphia Veterans Affairs Medical Center, VISN 4 Mental Illness Research, Education, and Clinical Center.

\section{Disclosure}

The authors report no conflicts of interest in this work.

\section{References}

1. Go AS, Mozaffarian D, Roger VL, et al; American Heart Association Statistics Committee and Stroke Statistics Subcommittee. Heart disease and stroke statistics - 2013 update: a report from the American Heart Association. Circulation. 2013;127(1):e6-e245.

2. Herr JK, Salyer J, Lyon DE, Goodloe L, Schubert C, Clement DG. Heart Failure Symptom Relationships: A Systematic Review. J Cardiovasc Nurs. Epub 2013 Jul 8.

3. Krumholz HM, Merrill AR, Schone EM, et al. Patterns of hospital performance in acute myocardial infarction and heart failure 30-day mortality and readmission. Circ Cardiovasc Qual Outcomes. 2009;2(5): 407-413.

4. Heidenreich PA, Albert NM, Allen LA, et al; American Heart Association Advocacy Coordinating Committee; Council on Arteriosclerosis, Thrombosis and Vascular Biology; Council on Cardiovascular Radiology and Intervention; Council on Clinical Cardiology; Council on Epidemiology and Prevention; Stroke Council. Forecasting the impact of heart failure in the United States: a policy statement from the American Heart Association. Circ Heart Fail. 2013;6(3):606-619.

5. Andrews RM, Elixhauser A. The national hospital bill: growth trends and 2005 update on the most expensive conditions by payer. Rockville, MD: Agency for Healthcare Research and Quality; 2007. Available from: http://www.hcup-us.ahrq.gov/reports/statbriefs/sb42. pdf. Accessed April 18, 2014.

6. Desai AS, Stevenson LW. Rehospitalization for heart failure: predict or prevent? Circulation. 2012;126(4):501-506.
7. Riegel B, Knafl GJ. Electronically monitored medication adherence predicts hospitalization in heart failure patients. Patient Prefer Adherence. 2013;8:1-13.

8. Wu JR, Moser DK, Lennie TA, Burkhart PV. Medication adherence in patients who have heart failure: a review of the literature. Nurs Clin North Am. 2008;43(1):133-153.

9. World Health Organisation. Overview: Medication Adherence-Where Are We Today? World Health Organization; 2006. Available from: http://www.adultmeducation.com/downloads/Adult_Med_Overview. pdf. Accessed April 18, 2014.

10. Riegel B, Lee CS, Ratcliffe SJ, et al. Predictors of objectively measured medication nonadherence in adults with heart failure. Circ Heart Fail. 2012;5(4):430-436.

11. AlGhurair SA, Hughes CA, Simpson SH, Guirguis LM. A systematic review of patient self-reported barriers of adherence to antihypertensive medications using the world health organization multidimensional adherence model. J Clin Hypertens (Greenwich). 2012;14(12):877-886.

12. Bender BG, Rand C. Medication non-adherence and asthma treatment cost. Curr Opin Allergy Clin Immunol. 2004;4(3):191-195.

13. Riegel B, Moelter ST, Ratcliffe SJ, et al. Excessive daytime sleepiness is associated with poor medication adherence in adults with heart failure. J Card Fail. 2011;17(4):340-348.

14. Brandt J, Folstein MF. Telephone Interview for Cognitive Status. Odessa, FL: Psychological Assessment Resources, Inc; 2003.

15. Jencks SF, Williams MV, Coleman EA. Rehospitalizations among patients in the Medicare fee-for-service program. N Engl J Med. 2009; 360(14):1418-1428.

16. Vrijens B, Tousset E, Rode R, Bertz R, Mayer S, Urquhart J. Successful projection of the time course of drug concentration in plasma during a 1-year period from electronically compiled dosing-time data used as input to individually parameterized pharmacokinetic models. J Clin Pharmacol. 2005;45(4):461-467.

17. Savic RM, Barrail-Tran A, Duval X, et al; ANRS 134-COPHAR 3 Study Group. Effect of adherence as measured by MEMS, ritonavir boosting, and CYP3A5 genotype on atazanavir pharmacokinetics in treatment-naive HIV-infected patients. Clin Pharmacol Ther. 2012; 92(5):575-583.

18. McNabb JJ, Nicolau DP, Stoner JA, Ross J. Patterns of adherence to antiretroviral medications: the value of electronic monitoring. AIDS. 2003;17(12):1763-1767.

19. Cramer J, Vachon L, Desforges C, Sussman NM. Dose frequency and dose interval compliance with multiple antiepileptic medications during a controlled clinical trial. Epilepsia. 1995;36(11):1111-1117.

20. Sutton S, Kinmonth AL, Hardeman W, et al. Does Electronic Monitoring Influence Adherence to Medication? Randomized Controlled Trial of Measurement Reactivity. Ann Behav Med. Epub 2014 Feb 27.

21. Lezak M, Howieson D, Lorig D. Neuropsychological Assessment. 4th ed. New York: Oxford University Press; 2004.

22. Green CP, Porter CB, Bresnahan DR, Spertus JA. Development and evaluation of the Kansas City Cardiomyopathy Questionnaire: a new health status measure for heart failure. J Am Coll Cardiol. 2000;35(5): 1245-1255.

23. Knafl GJ, Delucchi KL, Bova CA, Fennie KP, Ding K, Williams AB. A systematic approach for analyzing electronically monitored adherence data. In: Ekwall B, Cronquist M, editors. Micro Electro Mechanical Systems (MEMS) Technology, Fabrication Processes and Applications. Hauppauge, NY: Nova Science Publishers; 2010:1-66.

24. Knafl GJ, Bova CA, Fennie KP, O’Malley JP, Dieckhaus KD, Williams AB. An analysis of electronically monitored adherence to antiretroviral medications. AIDS Behav. 2010;14(4):755-768.

25. Delucchi KL, Knafl GJ, Haug N, Sorensen J. Adaptive Poisson modeling of medication adherence among HIV-positive methadone patients provided greater understanding of behavior. In: Ekwall B, Cronquist M, editors. Micro Electro Mechanical Systems (MEMS) Technology, Fabrication Processes and Applications. Hauppauge, NY: Nova Science Publishers; 2010:259-273. 
26. Knafl GJ, Schoenthaler A, Ogedegbe G. Secondary analysis of electronically monitored medication adherence data for a cohort of hypertensive African-Americans. Patient Prefer Adherence. 2016:207-219.

27. Kroenke K, Spitzer R, Williams J. The PHQ-9: Validity of a brief depression severity measure. Journal of General Internal Medicine. 2001; 16(9):606-613.

28. Hosmer DW, Lemeshow S. Applied Logistic Regression. 2nd ed. New York: John Wiley \& Sons; 2000.

29. Claxton AJ, Cramer J, Pierce C. A systematic review of the associations between dose regimens and medication compliance. Clin Ther. 2001;23(8):1296-1310.

30. Kardas P. Comparison of patient compliance with once-daily and twice-daily antibiotic regimens in respiratory tract infections: results of a randomized trial. J Antimicrob Chemother. 2007;59(3):531-536. Epub 2007 Feb 8.

31. Mastromarino V, Casenghi M, Testa M, Gabriele E, Coluccia R, Rubattu S, Volpe M. Polypharmacy in heart failure patients. Curr Heart Fail Rep. 2014;11(2):212-219.

32. Jansà $\mathrm{M}$, Hernández $\mathrm{C}$, Vidal $\mathrm{M}$, et al. Multidimensional analysis of treatment adherence in patients with multiple chronic conditions. A cross-sectional study in a tertiary hospital. Patient Educ Couns. 2010;81(2):161-168.

33. Dickson VV, Buck H, Riegel B. A qualitative meta-analysis of heart failure self-care practices among individuals with multiple comorbid conditions. J Card Fail. 2011;17(5):413-419.

34. Dickson VV, Buck H, Riegel B. Multiple comorbid conditions challenge heart failure self-care by decreasing self-efficacy. Nurs Res. 2013;62(1): 2-9.

35. Kripalani S, Yao X, Haynes RB. Interventions to enhance medication adherence in chronic medical conditions: a systematic review. Arch Intern Med. 2007;167(6):540-550.

36. Alfaro Lara ER, Vega Coca MD, Galván Banqueri M, et al. Selection of tools for reconciliation, compliance and appropriateness of treatment in patients with multiple chronic conditions. Eur J Intern Med. 2012;23(6):506-512.

37. Neupert SD, Patterson TR, Davis AA, Allaire JC. Age differences in daily predictors of forgetting to take medication: the importance of context and cognition. Exp Aging Res. 2011;37(4):435-448.

38. Quan SF, Chan CS, Dement WC, et al. The association between obstructive sleep apnea and neurocognitive performance - the Apnea Positive Pressure Long-term Efficacy Study (APPLES). Sleep. 2011;34(3): 303B-314B

39. McKenna BS, Dickinson DL, Orff HJ, Drummond SP. The effects of one night of sleep deprivation on known-risk and ambiguous-risk decisions. J Sleep Res. 2007;16(3):245-252.

40. Cameron J, Worrall-Carter L, Page K, Stewart S. Self-care behaviours and heart failure: does experience with symptoms really make a difference? Eur J Cardiovasc Nurs. 2010;9(2):92-100.

41. Francque-Frontiero L, Riegel B, Bennett J, et al. Self-care of persons with heart failure: Does experience make a difference? Clin Excel Nurse Pract. 2002;6:23-30.

42. Dickson VV, Deatrick JA, Riegel B. A typology of heart failure self-care management in non-elders. Eur J Cardiovasc Nurs. 2008;7(3): 171-181.

43. Vaduganathan M, Gheorghiade M, Butler J. Expanding the scope of the "polypill" to heart failure. J Card Fail. 2013;19(8):540-541.

44. Weaver TE, Chasens ER. Continuous positive airway pressure treatment for sleep apnea in older adults. Sleep Med Rev. 2007;11(2):99-111.

Patient Preference and Adherence

\section{Publish your work in this journal}

Patient Preference and Adherence is an international, peer-reviewed, open access journal that focuses on the growing importance of patient preference and adherence throughout the therapeutic continuum. Patient satisfaction, acceptability, quality of life, compliance, persistence and their role in developing new therapeutic modalities and compounds to optimize
45. NIH State of the Science Conference statement on Manifestations and Management of Chronic Insomnia in Adults statement. NIH Consens State Sci Statements. 2005;22(2):1-30.

46. Nowell PD, Mazumdar S, Buysse DJ, Dew MA, Reynolds CF 3rd, Kupfer DJ. Benzodiazepines and zolpidem for chronic insomnia: a metaanalysis of treatment efficacy. JAMA. 1997;278(24):2170-2177.

47. Krystal AD, Walsh JK, Laska E, et al. Sustained efficacy of eszopiclone over 6 months of nightly treatment: results of a randomized, doubleblind, placebo-controlled study in adults with chronic insomnia. Sleep. 2003;26(7):793-799.

48. Roth T, Walsh JK, Krystal A, Wessel T, Roehrs TA. An evaluation of the efficacy and safety of eszopiclone over 12 months in patients with chronic primary insomnia. Sleep Med. 2005;6(6):487-495.

49. Clarfield AM. Review: sedative-hypnotics increase adverse effects more than they improve sleep quality in older persons with insomnia. ACP J Club. 2006;145(1):14.

50. Curran HV, Collins R, Fletcher S, Kee SC, Woods B, Iliffe S. Older adults and withdrawal from benzodiazepine hypnotics in general practice: effects on cognitive function, sleep, mood and quality of life. Psychol Med. 2003;33(7):1223-1237.

51. Mitchell MD, Gehrman P, Perlis M, Umscheid CA. Comparative effectiveness of cognitive behavioral therapy for insomnia: a systematic review. BMC Fam Pract. 2012;13:40.

52. Riegel B, Hanlon AL, Zhang X, et al. What is the best measure of daytime sleepiness in adults with heart failure? J Am Assoc Nurse Pract. 2013;25(5):272-279.

53. Gladsjo JA, Heaton RK, Palmer BW, Taylor MJ, Jeste DV. Use of oral reading to estimate premorbid intellectual and neuropsychological functioning. J Int Neuropsychol Soc. 1999;5(3):247-254.

54. Uttl B. North American Adult Reading Test: age norms, reliability, and validity. J Clin Exp Neuropsychol. 2002;24(8):1123-1137.

55. Dahlem NW, Zimet GD, Walker RR. The Multidimensional Scale of Perceived Social Support: a confirmation study. Journal of Clinical Psychology. 1991;47(6):756-761.

56. Zimet GD, Powell SS, Farley GK, Werkman S, Berkoff KA. Psychometric characteristics of the Multidimensional Scale of Perceived Social Support. J Pers Assess. Winter 1990;55(3-4):610-617.

57. Charlson M, Pompei P, Ales K, MacKenzie C. A new method of classifying prognostic comorbidity in longitudinal studies: Development and validation. J Chronic Dis. 1987;40:373-383.

58. van der Wal M, Jaarsma T, Moser D, van Veldhuisen D. Development and testing of the Dutch Heart Failure Knowledge Scale. European Journal of Cardiovascular Nursing. August 2005.

59. Riegel B, Lee CS, Dickson VV, Carlson B. An Update on the SelfCare of Heart Failure Index. Journal of Cardiovascular Nursing. 2009; 24(6):485-497.

60. Johns MW. Reliability and factor analysis of the Epworth Sleepiness Scale. Sleep. 1992;15(4):376-381.

61. Hoddes E, Zarcone V, Smythe H, Phillips R, Dement WC. Quantification of sleepiness: a new approach. Psychophysiology. 1973;10(4): 431-436.

62. Buysse D, Reynolds, CF 3d, Monk, TH, Berman, SR, Kupfer, DJ. The Pittsburgh Sleep Quality Index: a new instrument for psychiatric practice and research. Psychiatr Res. 1989;28:193-213.

63. Basner M, Dinges DF. Maximizing sensitivity of the psychomotor vigilance test (PVT) to sleep loss. Sleep. 2011;34(5):581-591.

clinical outcomes for existing disease states are major areas of interest for the journal. This journal has been accepted for indexing on PubMed Central. The manuscript management system is completely online and includes a very quick and fair peer-review system, which is all easy to use. Visit http://www. dovepress.com/testimonials.php to read real quotes from published authors. 